\title{
PENGARUH TEMPERATUR DAN KOMPOSISI KIMIA TERHADAP SINTESIS ZEOLITE-Y BERBASIS LEMPUNG DAN ABU SEKAM PADI
}

\author{
*Armayani. M \\ Universitas Muhammadiyah \\ Sidenreng Rappang \\ armayanim@gmail.com \\ Musdalifa Mansur \\ Universitas Muhammadiyag \\ Sidenreng Rappang \\ musdalifa.mansur@gmail.com
}

\section{Subaer}

Universitas Negeri Makassar subaer@unm.ac.id

*koresponden author
Abstrak -Telah dilakukan sintesis zeolite-Y terhadap pengaruh temperatur dan komposisi kimia berbasis lempung dan abu sekam padi. Metode yang digunakan dalam penelitian ini yaitu hydrotermal dengan menggunakan autoclave variasi suhu yaitu $70 \quad \square$ dan $100 \square$ selama 3 jam dan variasi komposisi kimia $\mathrm{NaOH}, \mathrm{AlCl}_{3}$ serta $\mathrm{H}_{2} \mathrm{O}$. Bahan dasar Lempung diperoleh dari daerah Sidrap Sul-Sel dan abu sekam padi diperoleh dari pembakaran sekam. Zeolit hasil sintesis dilakukan pengujian XRF untuk megetahui unsur yang terkandung didalam bahan dasar, masing-masing $\mathrm{SiO}_{2}$ diperoleh sebesar 45,80 wt\% lempung dan $93,40 \%$ abu sekam padi, struktur kekristalan zeolit yang terbentuk dikarakterisasi dengan X-Ray Diffraction (XRD) berbentuk kristal dengan masing-masing zeolit yang terbentuk zeolit-Y dan Struktur mikro menggunakan Scanning Electron Microscopy (SEM).

Kata Kunci : Abu Sekam Padi, Autoclave, Lempung, dan Zeolite-Y

Abstract - The synthesis of zeolite-Y on the influence of temperature and chemical composition based on clay and rice husk ash has been carried out. The method used in this research is hydrothermal by using a temperature variation autoclave, namely $70 \square$ and $100 \square$ for 3 hours and variations in the chemical composition of $\mathrm{NaOH}, \mathrm{AlCl}_{3}$ and $\mathrm{H} 2 \mathrm{O}$. The basic material for clay is obtained from the Sidrap Sul-Sel area and rice husk ash is obtained from burning the husks. The zeolite as a result of the synthesis was carried out by XRF testing to determine the elements contained in the basic material, each $\mathrm{SiO}_{2}$ obtained was 45.80 $w t \%$ clay and $93.40 \mathrm{wt} \%$ rice husk ash, the crystalline structure of the zeolite formed was characterized by X-Ray Diffraction (XRD) in the form of crystals with each zeolite formed zeolite- $Y$ and microstructure using Scanning Electron Microscopy (SEM).

Keywords : Rice Husk Ash, Autoclave, Clay, and Zeolite-Y 


\section{A. PENDAHULUAN}

Zeolite merupakan kristal alumina silica yang mempunyai struktur kerangka tiga dimensi dengan rongga didalamnya. Struktur dan kerangka zeolite yang berongga membuat zeolite memiliki banyak kegunaan diantaranya sebagai absorben, penukar ion (ion exchange), sensor gas, katalis dan penyaring molekul (Fuadi, A.M., dkk. 2012; Ginting, E.M. 2017).

Zeolite biasa disintesis melalui metode solvothermal atau hidrothermal, dengan kondisi yang sesuai, kondisi yang dimaksud misalkan waktu dan suhu reaksi, sumber atom, agen mineralisasi, template dan temperatur kalsinasi (Koohsaryan E. dan Anbia M. 2016). Zeolite yang disintesis dengan metode hidrothermal pada umumnya menggunakan silika, alumina, dan kation logam sebagai prekursor dengan adanya template organic (Hartanto, D.,dkk. 2015). Silika yang digunakan sebagai reaktan bisa didapatkan dari berbagai sumber, pada umumnya tersedia secara komersial dalam baik dalam bentuk larutan, gel, padatan, koloid, atau turunan Zeolite merupakan kristal alumina silica yang mempunyai struktur kerangka tiga dimensi dengan rongga didalamnya. Struktur dan kerangka zeolite yang berongga membuat zeolite memiliki banyak kegunaan diantaranya sebagai absorben, penukar ion (ion exchange), sensor gas, katalis dan penyaring molekul (Fuadi, A.M., dkk. 2012; Ginting, E.M. 2017).

Zeolite biasa disintesis melalui metode solvothermal atau hidrothermal, dengan kondisi yang sesuai, kondisi yang dimaksud misalkan waktu dan suhu reaksi, sumber atom, agen mineralisasi, template dan temperatur kalsinasi (Koohsaryan E. dan Anbia M. 2016). Zeolite yang disintesis dengan metode hidrothermal pada umumnya menggunakan silika, alumina, dan kation logam sebagai prekursor dengan adanya template organic (Hartanto, D.,dkk. 2015). Silika yang digunakan sebagai reaktan bisa didapatkan dari berbagai sumber, pada umumnya tersedia secara komersial dalam baik dalam bentuk larutan, gel, padatan, koloid, atau turunan senyawa, organiknya, misalkan tetraetilortosilikat (Prasetyoko D., dkk. 2006).

Sekitar 20\% dari berat padi adalah sekam padi, dan bervariasi dari 13 sampai 29\% dari komposisi sekam adalah abu sekam yang selalu dihasilkan setiap kali sekam dibakar. Nilai paling umum kandungan silica $\left(\mathrm{SiO}_{2}\right)$ dalam abu sekam padi adalah 94-96\% (Prasetyoko D., dkk. 2006). Tingginya kandungan silica pada abu sekam padi, sehingga dapat dimanfaatkan dalam pembuatan material berbasis zeolite (Deviani, S.S., dkk. 2018).

Mineral lempung merupakan silikat yang berlapis; struktur kristal mineral-mineral tersebut tersusun dari lapisan tetrahedron $\mathrm{SiO}_{4}$. Di tengah tetrahedron $\mathrm{SiO}_{4}$ yang bergelang-6 biasanya terdapat ion hidroksil $(\mathrm{OH})$. Mineral-mineral lempung, terutama terdiri dari silikat aluminium dan/atau besi dan magnesium. Beberapa diantaranya juga mengandung alkali atau tanah alkalin sebagai komponen dasarnya. Mineral lempung berukuran sangat kecil (kurang dari 2 mikron) dan merupakan partikel yang aktif secara elektrokimiawi dan hanya dapat dilihat secara mikroskop electron (Subaer. 2012). 
Sintesis zeolite telah banyak diteliti sebelumnya, seperti pada Pattaraporn Lohsoontorn dan Paisan Konglachuichay (2006) berhasil mensintesis zeolite dari perlit dan abu sekam padi dengan menggunakan proses hidrotermal pada suhu 140 dan $170 \square$. Fuadi et al. (2012) berhasil mensintesis zeolit dari abu sekam padi melalui proses microwave dengan menvariasikan suhu dan waktu. Mohammed et al. (2015) memperoleh zeolit Y dalam bentuk natrium (NaY) disintesis menggunakan sumber silika dari abu sekam padi. Azizi dan Yousefpour (2010) mensintesis zeolite NaA dan analcime menggunakan abu sekam padi dengan menggunakan metode hidrotermal.

Pada riset ini akan dilakukan sintesis zeolite menggunakan metode hidrotermal dengan memanfaatkan limbah abu sekam padi dan lempung yang banyak terdapat di daerah Sidrap Sulawesi Selatan dimana, pada abu sekam padi dan lempung memiliki kandungan silica yang dapat digunakan sebagai bahan zeolit. Metode sintesis dengan bahan dasar seperti ini belum pernah dikaji sebelumnya. Oleh karenanya, studi diagram fasa, struktur mikro, dan kristal dari hasil sintesis zeolite tersebut perlu dilakukan sebagai langkah awal karakterisasi material fungsional baru.

\section{B. METODE}

Lempung yang digunakan sebagai bahan dasar zeolite berasal dari Kabupaten Sidrap, Sulawesi Selatan. Lempung tersebut dibersihkan dari pengotor dan direndam dengan Aquadest untuk memisahkan gumpalan partikel lempung yang berukuran besar. Hasil rendaman lempung ditapis kemudian dikeringkan di oven pada suhu $100 \square$ selama 2 jam. Lempung yang kering digerus hingga memperoleh ukuran butir partikel yang lebih kecil kemudian di ayak dengan ayakan 200 mesh. Hasil ayakan tersebut kemudian di dehidroksilasi selama 4 jam pada suhu $750 \square$.

Abu sekam padi yang digunakan sebagai campuran pembuatan zeolite berasal dari Kabupaten Sidrap, Sulawesi Selatan. Abu sekam padi yang diambil dari pabrik penggilingan padi terlebih dahulu direndam di dalam larutan $0,1 \mathrm{~mol} \mathrm{HCl}$ selama 4 jam. Larutan $\mathrm{HCl}$ dimaksudkan untuk melepaskan mineral pengotor yang melekat pada sekam padi. Hasil rendaman di cuci dengan aquadest beberapa kali hingga sisa larutan $\mathrm{HCl}$ hilang dan didehidroksilasi pada suhu $850 \square$ selama 4 jam.

Metode yang digunakan dalam pembuatan zeolite adalah metode hidrotermal menggunakan autoclave. Lempung dan abu sekam padi di aktivasi dengan menggunakan larutan $\mathrm{NaOH}$ dan $\mathrm{H}_{2} \mathrm{O}$ serta mencampurkan bahan $\mathrm{AlCl}_{3}$ sebanyak 2,5 gram.

Penambahan $\mathrm{NaOH}$ berfungsi sebagai kondisi basa pada saat sintesis zeolite $\mathrm{Na}-\mathrm{Y}$, dan juga untuk membentuk garam natrium alumina yang mudah larut sehingga dapat dikonversi menjadi zeolite. Kation $\mathrm{Na}^{+}$dari $\mathrm{NaOH}$ digunakan untuk menstabilkan muatan ion $\mathrm{Al}^{3+}$ dalam kerangka zeolite, selain itu juga dibutuhkan untuk sintesis zeolite dalam kondisi hidrotermal (Ojha, dkk., 2004).

Setelah semuanya bercampur kemudian dituang kedalam cetakan silinder dan dimasukkan kedalam autoclave dan dipanaskan kedalam oven selama 3 jam pada suhu $70 \square$ dan $100 \square$. 
Tabel 1. Komposisi Zeolit

\begin{tabular}{ccccc}
\hline \multirow{2}{*}{ Komposisi } & \multicolumn{4}{c}{ Massa Bahan (gram) } \\
\cline { 2 - 5 } & $\mathrm{NaOH}+\mathrm{H} 2 \mathrm{O}$ & $\mathrm{AlCl}_{3}$ & ASP & Lempung \\
\hline $\begin{array}{c}\mathrm{A}_{3} \mathrm{AlCl}_{3} \\
70 \square\end{array}$ & 20,5 & 25 & 5 & 25 \\
$\mathrm{~B}_{31} 100 \square$ & 25,5 & - & 5 & 25 \\
\hline
\end{tabular}

\section{HASIL DAN PEMBAHASAN}

\section{KARAKTERISASI XRF}

Hasil karakterisasi (XRF) bahan dasar lempung dan abu sekam padi terlihat pada tabel 2 dibawah ini. Perhitungan rasio molar oksida bahan awal untuk sintesis berdasarkan dari hasil $X$-ray fluorescence spectrometers (XRF).

Tabel 2. Hasil Karakterisasi XRF Bahan Dasar

\begin{tabular}{ccc}
\hline Unsur & Lempung (wt\%) & $\begin{array}{c}\text { Abu Sekam Padi } \\
(\mathrm{wt} \%)\end{array}$ \\
\hline $\mathrm{Al} 2 \mathrm{O} 3$ & 18,00 & - \\
$\mathrm{SiO} 2$ & 45,80 & 93,40 \\
$\mathrm{~K} 2 \mathrm{O}$ & 0,78 & 4,53 \\
$\mathrm{CaO}$ & 0,29 & 1,34 \\
$\mathrm{TiO} 2$ & 2,19 & - \\
$\mathrm{V} 2 \mathrm{O} 5$ & 0,13 & - \\
$\mathrm{Cr} 2 \mathrm{O} 3$ & 0,11 & - \\
$\mathrm{MnO}$ & 0,085 & 0,466 \\
$\mathrm{Fe} 2 \mathrm{O} 3$ & 32,71 & 0,13 \\
$\mathrm{NiO}$ & 0,030 & - \\
$\mathrm{CuO}$ & 0,12 & 0,071 \\
$\mathrm{ZnO}$ & 0,029 & 0,054 \\
$\mathrm{ZrO} 2$ & 0,11 & - \\
\hline
\end{tabular}

Dari Tabel di atas terlihat kandungan $\mathrm{SiO} 2$ pada masing-masing bahan dasar sangat tinggi yaitu $45,80 \mathrm{wt} \%$ lempung dan $93,40 \%$ abu sekam padi.

\section{KARAKTERISASI XRD}

Karakterisasi XRD dilakukan untuk mengidentifikasi fasa, parameter kisi, dan derajat kristalinitas yang terdapat pada setiap sampel.

Dapat Dilihat pula hasil XRD pada gambar 1. bahan dasar lempung sidrap suhu $750 \square$. Kandungan yang di dominasi oleh lempung adalah Quartz dan di ikuti oleh unsur lainnya seperti Magnetit dan dialuminum Silicate Oxide. Dimana intensitas yang paling tinggi berada $26.613{ }^{\circ}(2 \theta)$ yang dimiliki oleh Quartz. 


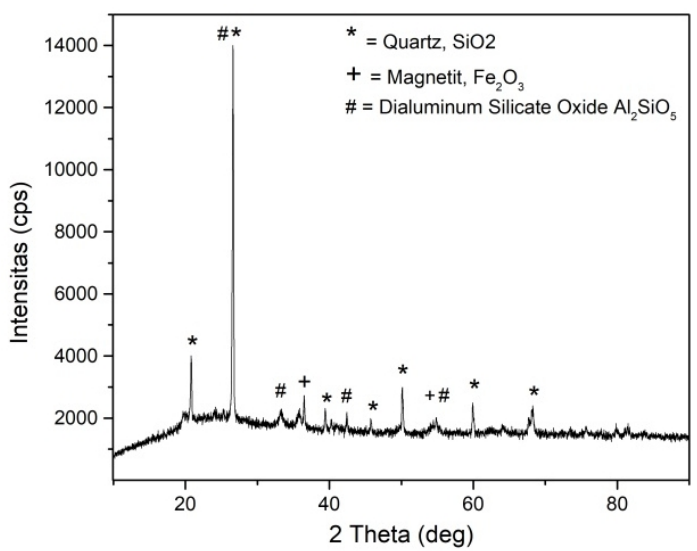

Gambar 1. Hasil Karakterisasi X-Ray Diffraction (XRD) Bahan Dasar Lempung.

Tabel 3. Data Analisis Qualitatif XRD

\begin{tabular}{lc}
\hline \multicolumn{1}{c}{ Nama Fase } & Kandungan (wt $\%)$ \\
\hline Dialuminum Silicate & 2,6 \\
Oxide, Sillimanite, High & 5,9 \\
Magnetite, syn & 92 \\
Quartz low, syn &
\end{tabular}

Dari data tersebut terlihat bahwa fase dominan yang terbentuk pada lempung sidrap yaitu fase Quartz yang terdiri dari $92 \mathrm{wt} \%$ (wt\% merupakan berat persen oksida yang telah dinormalisasi.

Abu sekam padi yang telah di dehidroksilasi pada suhu $850 \square$ dikarakterisasi menggunakan XRD pada gambar 2.

Gambar 2. Menunjukkan bahwa pola difraktogram $\mathrm{SiO}_{2}$ abu sekam padi berbentuk kristal, dengan intensitas paling tinggi berada pada puncak $23.281^{0}(2 \theta)$ yang dimiliki oleh Tridymite.

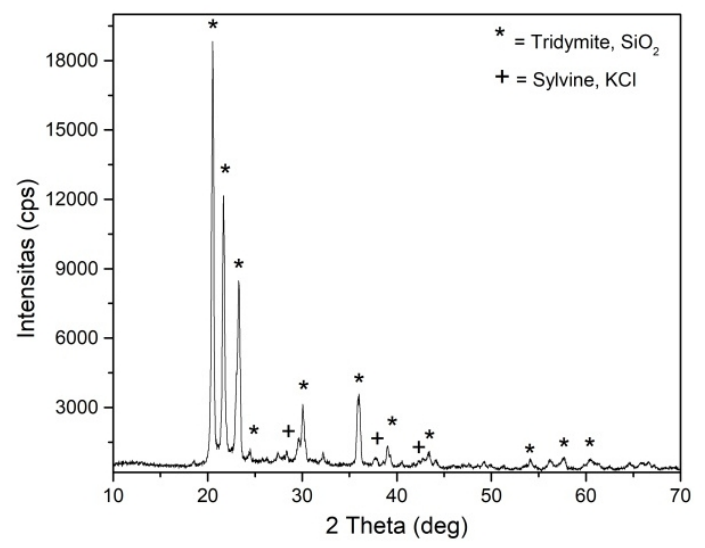

Gambar 2. Hasil Karakterisasi X-Ray Diffraction (XRD) Bahan Dasar Abu Sekam Padi.

Tabel 4. Data Analisis Qualitatif XRD

\begin{tabular}{lc}
\hline \multicolumn{1}{c}{ Nama Fase } & Kandungan $(w t \%)$ \\
\hline Tridymite, syn & 99,5 \\
Sylvine & 0,5 \\
\hline
\end{tabular}


Dan dari persentase tabel 4. Data XRD terlihat bahwa fase dominan yang terbentuk pada abu sekam padi yaitu fase Tridymite, syn sebesar 99,5 wt\% dan terdapat pengotor $\mathrm{KCl}$ (Sylvine) sebesar $0,5 \mathrm{wt} \%$. Senyawa yang mengandung kalium merupakan salah satu pengotor utama dalam sekam padi yang keberadaannya sangat mengganggu proses isolasi silika murni dari sekam padi (Sapei. L., dkk. 2008).Dengan demikian abu sekam padi dijadikan sebagai sumber $\mathrm{SiO}_{2}$ dalam sintesis Zeolit Y.

Hasil Difraktogram XRD dari pencampuran bahan dasar lempung dan abu sekam padi dapat dilihat pada gambar 3. Berdasarkan data yang diperoleh menggunakan PDXL II, terdapat fase Quartz, Trydimite, Zeolit Y, dan Hematite.

Pola difraktogram zeolite hydrothermal hasil uji XRD yang ditunjukkan gambar 3.dengan menggunakan suhu $100 \square$, kristalinitas terbentuk tinggi. Terlihat pada perbandingan suhu $70 \square$ yang masih terdapat punukan (Gundukan).

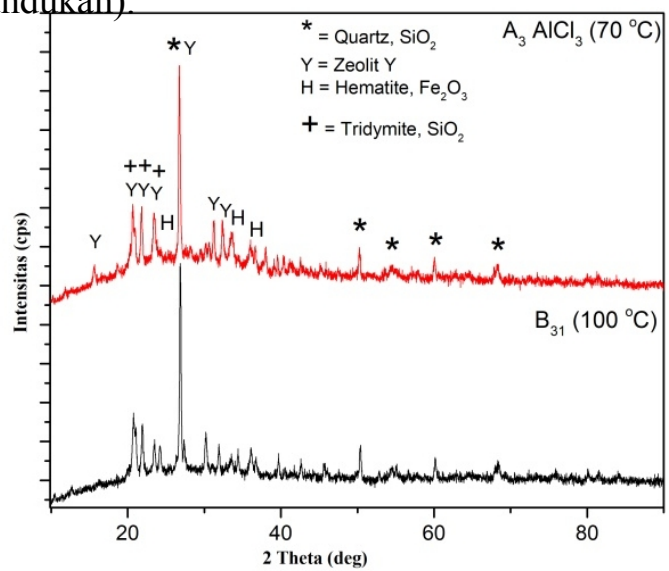

Gambar 3. Hasil Karakterisasi X-Ray Diffraction (XRD) $\mathrm{A}_{3} \mathrm{AlCl}_{3}$ suhu $70 \square$ dan $\mathrm{B}_{31}$ suhu $100 \square$.

Puncak dengan intensitas tinggi terdapat pada $2 \theta=15,61^{0} ; 20,950^{\circ} ; 21,794^{0} ; 23,44^{0} ; 26,737^{0}$; $33,59^{0} ; 35,97^{0}$; dan $41,15^{\circ}$ pada suhu $100 \square$. Sedangkan puncak dengan intensitas tinggi terdapat pada $2 \theta=20,752^{0} ; 21,880^{0} ; 23,48^{0} ; 26,851^{0} ; 30,21^{0} ; 36,16^{0} ;$ dan $54,41^{0}$ pada suhu $70 \square$.

Tabel 5. Data Analisis Qualitatif XRD

\begin{tabular}{|c|c|c|}
\hline Nama Fase & $\begin{array}{c}\mathrm{A}_{3} \mathrm{AlCl}_{3} 70 \square \\
(\mathrm{wt} \%)\end{array}$ & $\begin{array}{c}\mathrm{B}_{31} 100 \\
(\mathrm{wt} \%)\end{array}$ \\
\hline Tridymite, syn & 36 & 4,5 \\
\hline quartz low HP, syn & 45 & 58 \\
\hline Zeolite Y, (Na) & 9 & 28 \\
\hline $\begin{array}{l}\text { Iron diiron(III) oxide, } \\
\text { magnetite low }\end{array}$ & 10 & 9.6 \\
\hline
\end{tabular}

Hasil pencampuran bahan dasar lempung dan abu sekam padi dengan menggunakan variasi suhu, alkali dan $\mathrm{AlCl}_{3}$ diperoleh zeolite-Y (Na) hal ini dapat dilihat dari sampel $\mathrm{A}_{3} \mathrm{AlCl}_{3} 70 \square$ dan $\mathrm{B}_{31} 100$ $\square$, semakin tinggi suhu yang diberikan semakin tinggi fase zeolite-Y dihasilkan. Sampel Zeolit-Y tidak terbentuk sempurna dikarenakan lempung sidrap yang memiliki kandungan $\mathrm{Fe}_{2} \mathrm{O}_{3}$ yang tidak bisa dihilangkan walupun sudah disintesis. 
Berbeda dengan penelitian yang dilakukan oleh Arnelli, dkk. 2017 sintesis zeolit yang dilakukan pada suhu hidrotermal $150{ }^{\circ} \mathrm{C}$ memberikan hasil berupa difraktogram yang berbeda daripada difraktogram zeolit yang disintesis pada suhu hidrotermal $50{ }^{\circ} \mathrm{C}$ dan $100{ }^{\circ} \mathrm{C}$. Pada suhu 50 ${ }^{\circ} \mathrm{C}$ dan $100^{\circ} \mathrm{C}$ diperoleh zeolite-A dan pada suhu $150{ }^{\circ} \mathrm{C}$ diperoleh Zeolite-Y.

\section{KARAKTERISASI SEM}

Karakterisasi dengan SEM dilakukan untuk mengidentifikasi morfologi permukaan kristal zeolite-Y yang terbentuk. Hasil Karakterisasi bahan dasar lempung sidrap disajikan pada gambar 4.

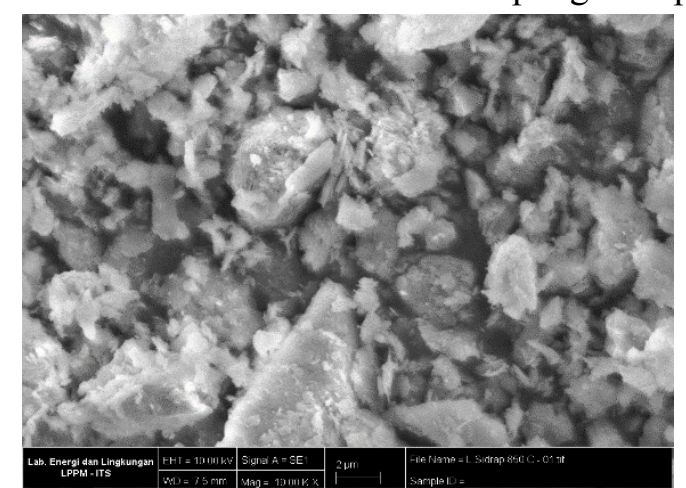

Gambar 4. Hasil Karakterisasi Scanning Electron Microscopy (SEM) Bahan Dasar Lempung perbesaran $10.000 \mathrm{kx}$.

Terlihat morfologi lempung sidrap dengan perbesaran $10.000 \mathrm{kx}$ menunjukkan butiran dengan ukuran yang bervariasi. Skala putih citra SEM yang relative tidak seragam menandakan komposisi kimia material dengan nomor atom yang sama yakni Fe.
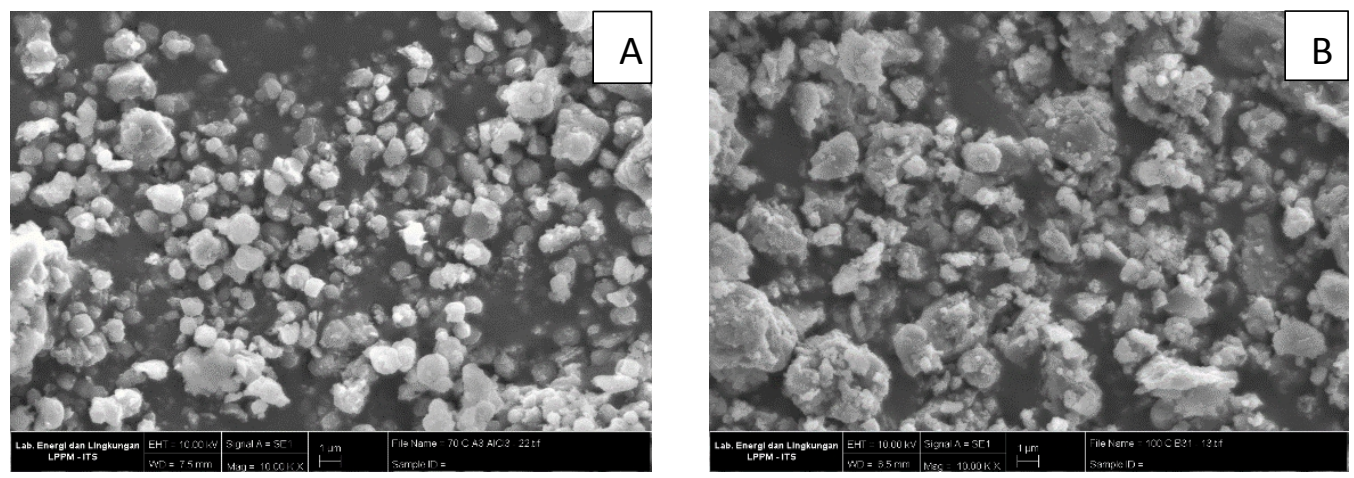

Gambar 5. Hasil Karakterisasi Scanning Electron Microscopy (SEM) Zeolit perbesaran $10.000 \mathrm{kx}$ A) A3 $\mathrm{AlCl}_{3}$ Suhu $70 \square$, dan B) B31 Suhu $100 \square$

Morfologi sampel zeolite-Y hasil karakterisasi Scanning Electron Microscopy (SEM) pada gambar A dan B, dengan perbesaran $10.000 \mathrm{kx}$ terlihat memiliki ukuran butir yang bervariasi dengan bentuk bulat yang tidak beraturan dengan kisaran kurang lebih $1 \mu \mathrm{m}$. morfologi pada zeolit $\mathrm{A} 3 \mathrm{AlCl}_{3}$ Suhu $70 \square$ terlihat memiliki ukuran partikel yang agak kecil dibandingkan dengan zeolite B31 Suhu $100 \square$. 


\section{SIMPULAN}

Dari hasil penelitian yang telah dilakukan, maka diperoleh simpulan bahwa pembuatan zeolite-Y dengan menggunakan bahan dasar lempung dan abu sekam padi dapat terbentuk pada zeolite A3 $\mathrm{AlCl}_{3}$ Suhu $70 \square$ dan zeolite B31 Suhu $100 \square$ dengan menggunakan variasi suhu hydrotermal dan komposisi kimia. Semakin tinggi suhu yang diberikan dan semakin tinggi komposisi $\mathrm{NaOH}$ dan $\mathrm{H}_{2} \mathrm{O}$ maka diperoleh komposisi zeolit-Y yang semakin besar.

\section{UCAPAN TERIMA KASIH}

Penelitian ini telah di danai oleh PDP kemenristek Dikti No.189/SP2H/AMD/LT/DRPM/2020.

\section{DAFTAR RUJUKAN}

Fuadi, A.M., Musthofa, M., Harismah, K., Haryanto and Hidayati, N. (2012), "Pembuatan Zeolit Sintetis Dari Sekam Padi”, Simposium Nasional RAPI XI FT UMS-2K012, pp. K55-K62.

Ginting, E.M. (2017), "Struktur dan Morfologi Nano Komposit Campuran Zeolit Abu Sekam Padi”, Jurnal Material dan Energi Indonesia, Vol. 7 No. 01.

Koohsaryan E. dan Anbia M. (2016). "Nanosized and Hierarchical Zeolites: A Short Review". Chinese Journal of Catalysis, 37 (4), 447-467.

Hartanto, D., Saputro, O., Utomo, W.P., Rosyidah, A., Sugiarso, D., Ersam, T., Nur, H., dan Prasetyoko, D. (2015). "Synthesis of ZSM-5 Directly from Kaolin without Organic Template: Part-1: Effect of Crystallization Time", Asian Journal of Chemistry, 28(1), 211-215.

Prasetyoko D., Ramli Z., Endud S., Hamdan H., dan Sulikowski B. (2006). Conversion of Rice Husk Ash to Zeolite Beta. Waste Management, 26, 1173-1179.

Deviani, S.S., Mahatmanti, F.W. and Widiarti, N. (2018), "Sintesis dan Karaketrisasi Zeolit dari Abu Sekam Padi Menggunakan Metode Hidrotermal". Indonesian Journal of Chemical Science, Vol. 7 No. 1, pp. 86-93.

Subaer, 2012. "Pengantar Fisika Geopolimer, Direktorat Jenderal Pendidikan Tinggi”, Makassar.

Kongkachuichay, P. and Lohsoontorn, P. (2006), "Phase Diagram of Zeolite Synthesized from Perlite and Rice Husk Ash", ScienceAsia, Vol. 32 No. 1, p. 013.

Mohamed, R.M., Mkhalid, I.A. and Barakat, M.A. (2015), "Rice husk ash as a renewable source for the production of zeolite $\mathrm{NaY}$ and its characterization", Arabian Journal of Chemistry, Vol. 8 No. 1, pp. 48-53.

Azizi, S.N. and Yousefpour, M. (2010), "Synthesis of zeolites NaA and analcime using rice husk ash as silica source without using organic template", Journal of Materials Science, Vol. 45 No. 20, pp. 5692-5697.

Ojha, K., Narayan C.P., dan Amar, N.T. 2004. Zeolite from Fly Ash: Synthesis and Characterization. Journal Sci., Vol. 27(6): 555-564.

Sapei.L., Nöske.R., Strauch.P., Paris.O., 2008. Isolation of Mesoporous Biogenic Silica from the Perennial Equisetum hyemale. Chem. Mater 20, 2020-2025.

Arnelli, Fitriani Solichah, Alfiansyaha, Ahmad Susenoa, Yayuk Astuti. 2017. Sintesis Zeolit dari Abu Sekam Padi menggunakan Metode Hidrotemal :Variasi Waktu dan Temperatur. Jurnal Kimia Sains dan Aplikasi 20 (2) (2017) : 58 - 61. 